\title{
O mapeamento geomorfológico como subsídio ao estudo das fragilidades ambientais
}

The geomorphological mapping as a subsidy to the study of environmental fragilities

Marilene Dias do Nascimento e Bernardo Sayão Penna e Souza

Universidade Federal de Santa Maria - Santa Maria - RS- Brasil

\section{Resumo}

O presente trabalho teve como objetivo principal a realização do estudo integrado dos elementos físicos e antrópicos da paisagem da Região Administrativa Nordeste da cidade de Santa Maria, a partir do estudo do relevo com a delimitação das Unidades Morfológicas (Ross, 1992), definidas pelos padrões de formas semelhantes do relevo, a fim de identificar áreas de fragilidade ambiental e proporcionar subsídios para o planejamento ambiental integrado. Constatou-se, com este estudo, que a unidade morfológica de morros, correspondente a 48,9\% da área estudada, apresenta as maiores fragilidades ambientais e, por isso, pode ser considerada fortemente instável, pois o equilíbrio natural vem sendo afetado pelas modificações antrópicas introduzidas na paisagem.

Palavras-chaves: geomorfologia; fragilidade ambiental; planejamento urbano.

\begin{abstract}
This research aims at the integrated study of physical and anthropic elements that make up the landscape of northeastern portion of the city of Santa Maria-RS, from the delimitation of Morphological Units (Ross, 1992), defined by the patterns of forms with similar relief. It was found that the Morphological Unit of Hills, corresponding to $48.9 \%$ in the study area has the highest environmental fragilities and therefore can be considered highly unstable, since the natural balance has been affected by the modifications introduced in the anthropic landscape.
\end{abstract}

Keywords: geomorphology; environmental fragility; urban planning. 


\section{Introdução}

O relevo, como recurso da natureza, é o palco no qual se realizam as atividades humanas, onde acontecem as relações sociais, econômicas e políticas. Assim sendo, o relevo constitui-se o suporte de todos os modelos de desenvolvimento que ocorrem ao longo do processo de ocupação humana dos espaços terrestres. Essa ocupação, muitas vezes, gera desequilíbrios no ambiente natural e uma crescente degradação da terra que, consequentemente, culmina em uma considerável perda da qualidade de vida pelas populações. Penteado (1981, p. 3) afirma que

[...] o homem tem capacidade de alterar os processos de elaboração do relevo, modificando solos, vegetação, condições hidrográficas, formas de erosão e introduzindo tais modificações no sistema morfológico, que podem conduzir ao desequilíbrio e colapso.

Considera-se assim, a relevância do estudo geomorfológico no que se refere à execução de planejamentos de utilização dos recursos naturais, visando ao desenvolvimento sustentável. Faz-se conveniente, no entanto, não só o estudo geomorfológico isolado, mas a realização de um estudo integrado e sistêmico dos elementos físicos naturais, biológicos e antrópicos, para o melhor entendimento dos processos de modificação da paisagem e a sua reconstituição e/ou preservação.

Para Ross (1996), o conhecimento das potencialidades dos recursos naturais de um determinado sistema natural passa pelos levantamentos dos solos, relevo, rochas e minerais, da água, do clima, da flora e fauna, enfim, de todos os componentes que dão suporte à vida animal e ao homem.

Dentro desse contexto, o presente estudo teve como objetivo principal a realização do estudo integrado dos elementos físicos (solos, geologia, vegetação, clima e hidrografia) e antrópicos (uso e ocupação da terra) da paisagem da Região Administrativa Nordeste da Sede do Município de Santa Maria, a partir da delimitação das Unidades Morfológicas (Ross, 1992), definidas pelos padrões de formas semelhantes do relevo, a fim de identificar áreas de fragilidade ambiental e proporcionar subsídios para o planejamento ambiental integrado.

\section{Procedimentos metodológicos}

A metodologia utilizada para a realização desta pesquisa consistiu, primeiramente, na individualização das Unidades Morfológicas da Região
Administrativa Nordeste da Sede do Município de Santa Maria, considerando o terceiro táxon de análise, dentro da proposta de taxonomia de relevo desenvolvida por Ross (1992). Esses padrões de formas semelhantes são conjuntos de formas menores de relevo, que apresentam distinções de aparência entre si em função da rugosidade topográfica e do formato dos topos, vertentes e vales de cada padrão existente e é onde os processos morfoclimáticos atuais começam a ser mais facilmente notados.

Em seguida, a fim de realizar o estudo integrado da paisagem e a determinação das fragilidades ambientais presentes em cada Unidade Morfológica, foram elaborados os mapas temáticos dos demais elementos físico-naturais (declividade, geologia e solos) e dos elementos antrópicos (uso da terra e cobertura vegetal) que compõem a paisagem e a determinação das classes hierárquicas de fragilidade de cada tema estudado. A partir da geração desses mapas, foram analisadas cada uma das Unidades Morfológicas individualizadas.

As fragilidades ambientais foram determinadas a partir da ponderação das classes de fragilidade dos elementos físico-naturais e dos elementos antrópicos que compõem cada Unidade Morfológica da área de estudo.

O Mapa Clinográfico foi elaborado com base nas classes de declividades propostas por Ross (1994). Esse autor descreve que, para análise de fragilidade do ambiente em terrenos com escalas de maior detalhe como, por exemplo, 1:25000, deve-se utilizar os intervalos de declividade já consagrados nos estudos de capacidade de uso e aptidão agrícola, associados com aqueles conhecidos como valores limites críticos da geotecnia, que indicam o vigor dos processos erosivos. Deste modo, estas classes são representadas pelos seguintes intervalos: $<3,3$ a $6 \%, 6$ a $12 \%, 12$ a $20 \%, 20$ a $30 \%, 30$ a $50 \%$ e $>50 \%$.

Ross (1994) organizou essas classes em 5 categorias hierárquicas para que fossem utilizadas na elaboração de mapas de fragilidades ambientais da seguinte forma: fragilidade muito fraca - até $6 \%$, fraca - de 6 a 12\%, média - de 12 a 20\%, forte - de 20 a $30 \%$ e muito forte - acima de $30 \%$.

O Mapa Geológico foi compilado a partir do georreferenciamento do Mapa Geológico, Folha de Santa Maria, escala 1:50000, elaborado por Gasparetto et al. (1988) e da vetorização das formações geológicas e processos de dinâmica superficial descritos por este.

Com base nesse Mapa Geológico, foram individualizadas, na área de estudo, quatro tipos de formações distintas: Formação Santa Maria, Formação Caturrita, Formação Botucatu e Formação Serra Geral. As categorias hierárquicas do grau de fragi- 
lidade foram definidas com base nas propriedades geotécnicas de cada formação geológica identificadas por Maciel Filho (1990) e pelas declividades onde são encontradas. Assim, os graus de fragilidade das formações geológicas foram definidos da seguinte forma: Formação Santa Maria (fraca), Formação Caturrita (média), Formação Botucatu (forte), Formação Serra Geral (muito forte), Formação Santa Maria com depósitos fluviais (muito forte), Formação Caturrita com depósitos de colúvio (muito forte) e Formação Botucatu com depósitos de colúvio (muito forte).

As classes de solos identificadas no Mapa de Solos foram compiladas do mapeamento realizado por Pedron (2005), na escala 1:25000. Este foi adaptado ao novo Sistema Brasileiro de Classificação de Solos, da Embrapa Solos (2005). O grau de fragilidade dos solos foi definido considerando Pedron (2005) e Ross (1994).

Dessa forma, as categorias hierárquicas de fragilidade das classes de solos foram definidas como: os Planossolos Háplico Eutrófico gleissólico (SXe), os Argissolos Vermelho-Amarelo Ta Distrófico abrúptico (PVAvd1) e os Argissolos Vermelho Eutrófico espessarênico (PVe ), como sendo de fragilidade média; os Argissolos Bruno-Acinzentado Alítico típico (PBa+Cal), os Argissolos Bruno-Acinzentado Alítico abrúptico (PBACal2 e PBACal3), como fragilidade forte e os Neossolos Regolítico Eutrófico léptico (PVe), os Neossolos Flúvico Psamítico típico Forte (RRe2), os Neossolos Regolítico Eutrófico léptico (RUq), os Neossolos Regolítico Eutrófico léptico + Neossolos Litólico Eutrófico fragmentário (RRe2+RLe) e os Neossolos Regolítico Eutrófico léptico (RRel), como fragilidade muito forte

As informações relativas ao uso da terra são representadas nesse trabalho pelas atividades antrópicas e pela cobertura vegetal.

Considerando o tipo de uso da terra, Ross (1994) propôs uma classificação de graus de proteção. Dessa forma, no presente trabalho, as áreas com florestas foram consideradas com grau de proteção muito forte e fragilidade muito fraca. A vegetação campestre (vegetação rasteira), com grau forte de proteção, apresenta fragilidade fraca. As áreas com predomínio de uso agrícola e/ou pastagens apresentam um grau médio de fragilidade e de proteção também média, e a área urbana com grau de proteção baixa apresenta fragilidade forte a muito forte.

O Mapa de Uso da Terra e Cobertura Vegetal foi elaborado a partir da classificação digital da imagem dos sensores HRC e CCD do satélite CBERS-2B de 25/11/2011. As imagens foram adquiridas no banco de imagens da Divisão de Geração de Informação (DGI) do Instituto Nacional de Pesquisas Espaciais (INPE). Nas imagens, foi realizado o processo de fusão usando a técnica de transformação do espaço de cores
RGB para o IHS e de IHS para RGB. A partir disso, foi aplicado o realce sobre as imagens para a análise visual das mesmas. O método da classificação digital supervisionada foi utilizado para obter o mapeamento do uso do solo e cobertura vegetal.

Os mapas temáticos foram elaborados no Sistema de Geoprocessamento SPRING 4.3, onde foram gerados os Planos de Informações (PIs) correspondentes a estes mapas.

Também foram elaborados diversos trabalhos de campo, no decorrer da pesquisa, a fim de verificar as feições morfológicas, as formas de vertentes, os usos da terra e os processos atuais individualizados, preliminarmente, no estudo de gabinete, bem como a coleta de dados adicionais e observação empírica da área de estudo, para ajustes no trabalho de gabinete.

\section{Resultados e discussões}

\subsection{Localização e caracterização geral da área de estudo}

Segundo o Plano Diretor de Desenvolvimento Urbano Ambiental de Santa Maria (2006) a sede do município está dividida em quarenta e um bairros distribuídos em oito Regiões Administrativas (R.A.). São elas: Região Administrativa Centro Urbano; Região Administrativa Leste; Região Administrativa Norte; Região Administrativa Centro-Leste; Região Administrativa Nordeste; Região Administrativa Sul; Região Administrativa Centro-Oeste e Região Administrativa Oeste.

A Região Administrativa Nordeste (Figura 1), no contexto urbano de Santa Maria/RS, situa-se na porção nordeste da sede do município, entre as coordenadas geográficas de $29^{\circ} 37^{\prime} 30^{\prime \prime}$ e $29^{\circ} 41^{\prime} 30^{\prime \prime}$ de latitude sul e de $53^{\circ} 46^{\prime} 00^{\prime \prime}$ a $53^{\circ} 49^{\prime} 00^{\prime \prime}$ de longitude oeste. Ocupa uma área de $19 \mathrm{Km}^{2}$ e conta com uma população total de 28.819 habitantes (IBGE, 2010).

Essa área foi escolhida para a realização deste estudo porque vem sendo submetida a um processo de ocupação urbana desordenada que coincide, em particular, com a área de transição do Rebordo do Planalto, localizado entre a Porção Sul dos Planaltos e Chapadas da Bacia do Paraná, ao norte, e a Depressão Periférica Sul-rio-grandense, planícies fluviais do rio Vacacaí-Mirim, ao sul.

Os bairros que compõem a R. A. Nordeste são: Campestre do Menino Deus, Itararé, Quilômetro Três, Menino Jesus, Nossa Senhora das Dores e Presidente João Goulart.

O bairro Campestre do Menino Deus possui uma área de 10,6 Km². Segundo Goldani et al (2008), a 


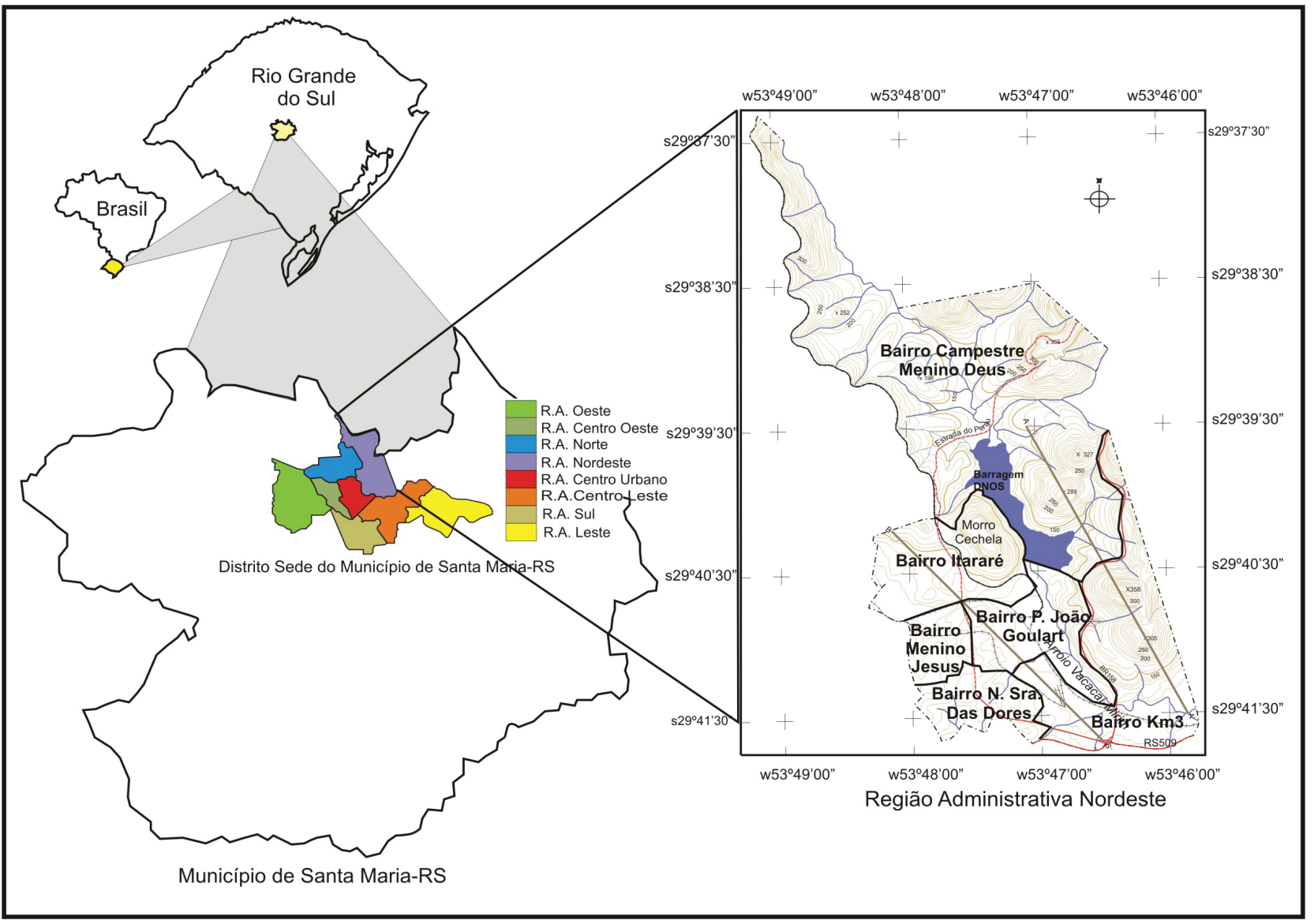

Figura 1 - Localização da Região Administrativa Nordeste

ocupação desse bairro deu-se no entorno da sub-bacia do rio Vacacaí Mirim, ao norte da barragem do Departamento Nacional de Obras e Saneamento (DNOS) e do morro Cechela. Apresenta impacto ambiental em decorrência da ocupação desordenada que exerce forte pressão sobre áreas de preservação ambiental (GOLDANI et al, 2008).

O bairro Itararé possui uma área de $2,31 \mathrm{Km}^{2}$. Caracteriza-se por ser bem urbanizado e destina-se, exclusivamente, ao uso residencial. Possui elevada presença de vegetação do tipo arbórea e fraco fluxo de veículos e pessoas.

O bairro Quilômetro Três, com uma área de 3,48 km², tem como Unidades Residenciais o Quilômetro Três, a vila Anacleto Correa, a vila Bilibio, a vila Dr. Wautier, a vila Favarin e a vila Palmares.

O bairro Menino Jesus é composto pelas Unidades Residenciais Menino Jesus, vila Leste, vila Major Duarte (parte fica no bairro Centro) e vila Ponte Seca. Possui uma área de $0,59 \mathrm{Km}^{2}$.

O bairro Nossa Senhora das Dores possui uma área de $1.08 \mathrm{Km}^{2}$ para 4.656 habitantes (IBGE, 2010). Localiza-se na proximidade do bairro Centro e caracteriza-se por ser bem urbanizado, destinado ao uso residencial, classe média, com elevada densidade populacional, em torno dos $4.311 \mathrm{Hab} /$ $\mathrm{km}^{2}$, onde predominam as edificações mais baixas, com exceção da avenida Nossa Senhora das Dores, onde destacam-se as edificações mais elevadas e grande concentração comercial com intenso fluxo de veículos. Trata-se do bairro mais urbanizado da R. A. Nordeste.

O bairro Presidente João Goulart possui uma área de $1,75 \mathrm{~km}^{2}$. O rio Vacacaí-Mirim e a Linha Férrea foram os principais pontos de atração populacional para este bairro. Tal rio, no início da formação do bairro propiciava aos seus habitantes uma área de lazer. Atualmente, devido à crescente urbanização, encontra-se poluído e sem condições de qualquer tipo de uso. Quanto à via férrea, há época de sua construção, atraia para suas proximidades um contingente de funcionários da Rede Ferroviária Federal, muitos dos quais foram ali residir, buscando a proximidade do local de trabalho. 


\subsection{As Unidades morfológicas}

A área abrangida pela R. A. Nordeste, em razão de suas características geomorfológicas, teve identificadas três unidades morfológicas distintas:
I) Unidade de Morros; II) Unidade de Colinas e III) Unidade de Planície Fluvial (Figura 2).

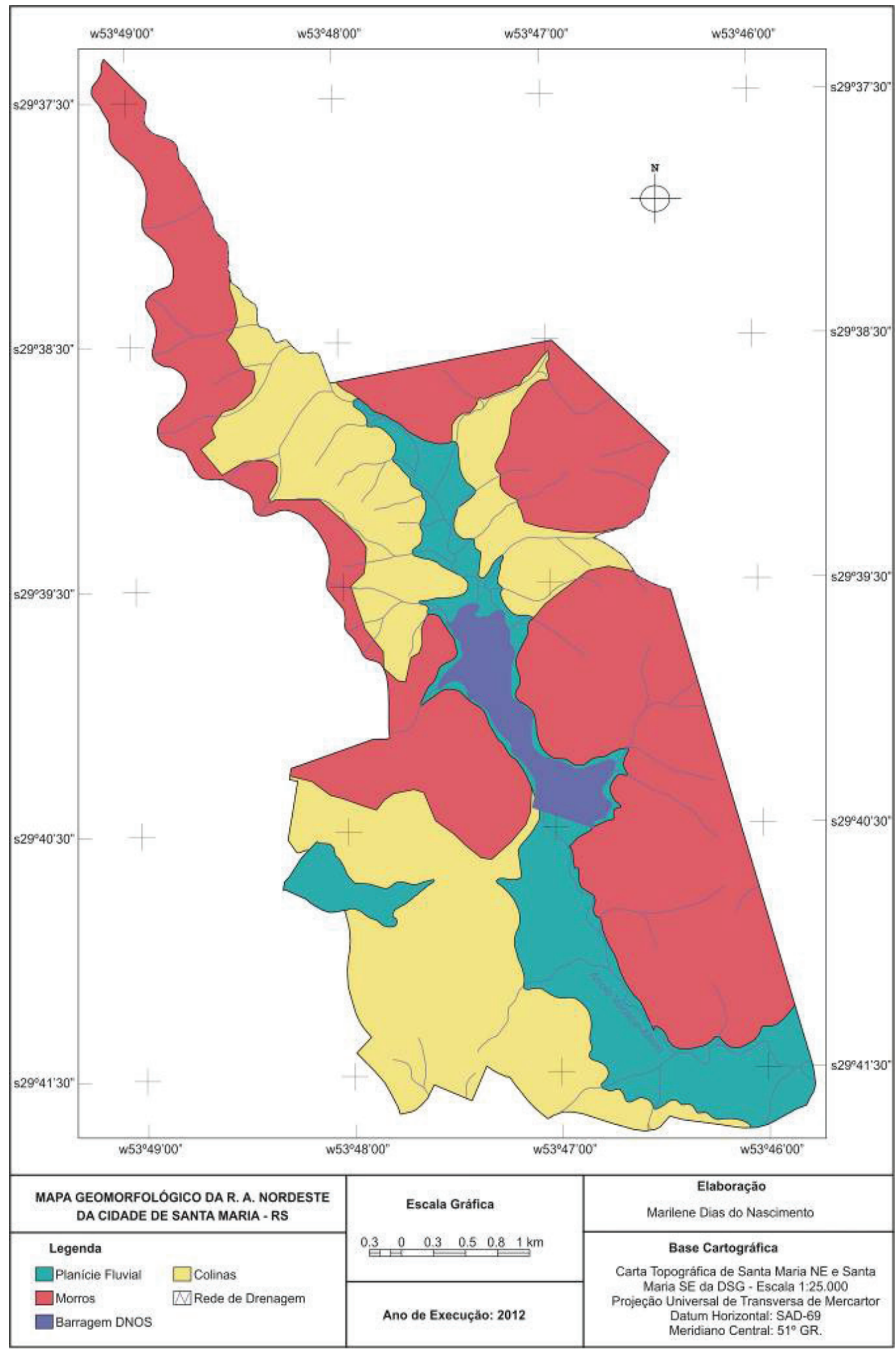

Figura 2 - Mapa Geomorfológico da R. A. Nordeste 


\subsubsection{Unidade Morfológica de Morros}

A declividade acentuada das vertentes (Figura 3) associada ao volume e à intensidade das chuvas e à retirada da cobertura vegetal pela atividade agrícola e pela ocupação urbana não planejada, conferem a essa unidade uma elevada suscetibilidade aos processos erosivos.

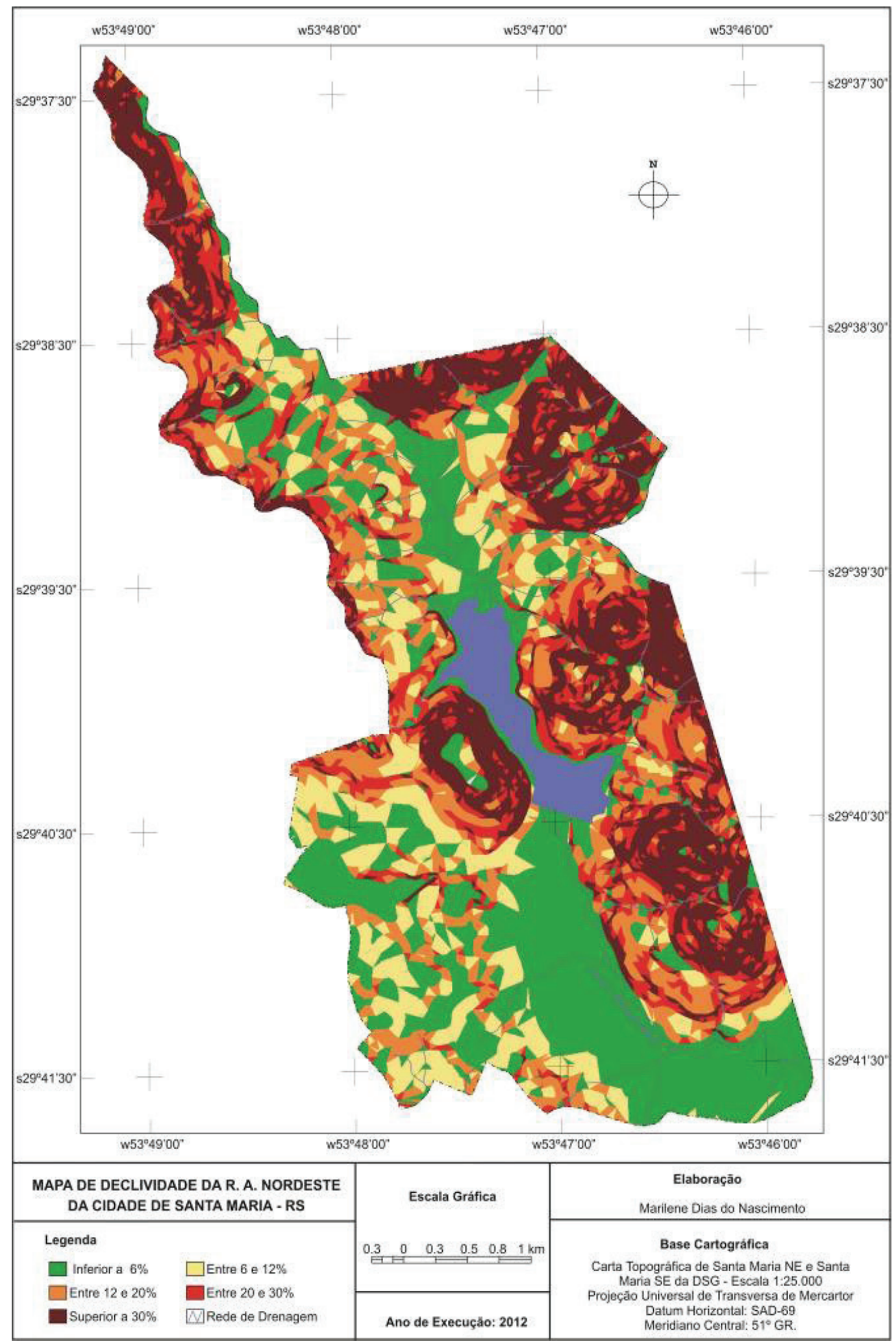

Figura 3 - Mapa de Declividades da R. A. Nordeste 


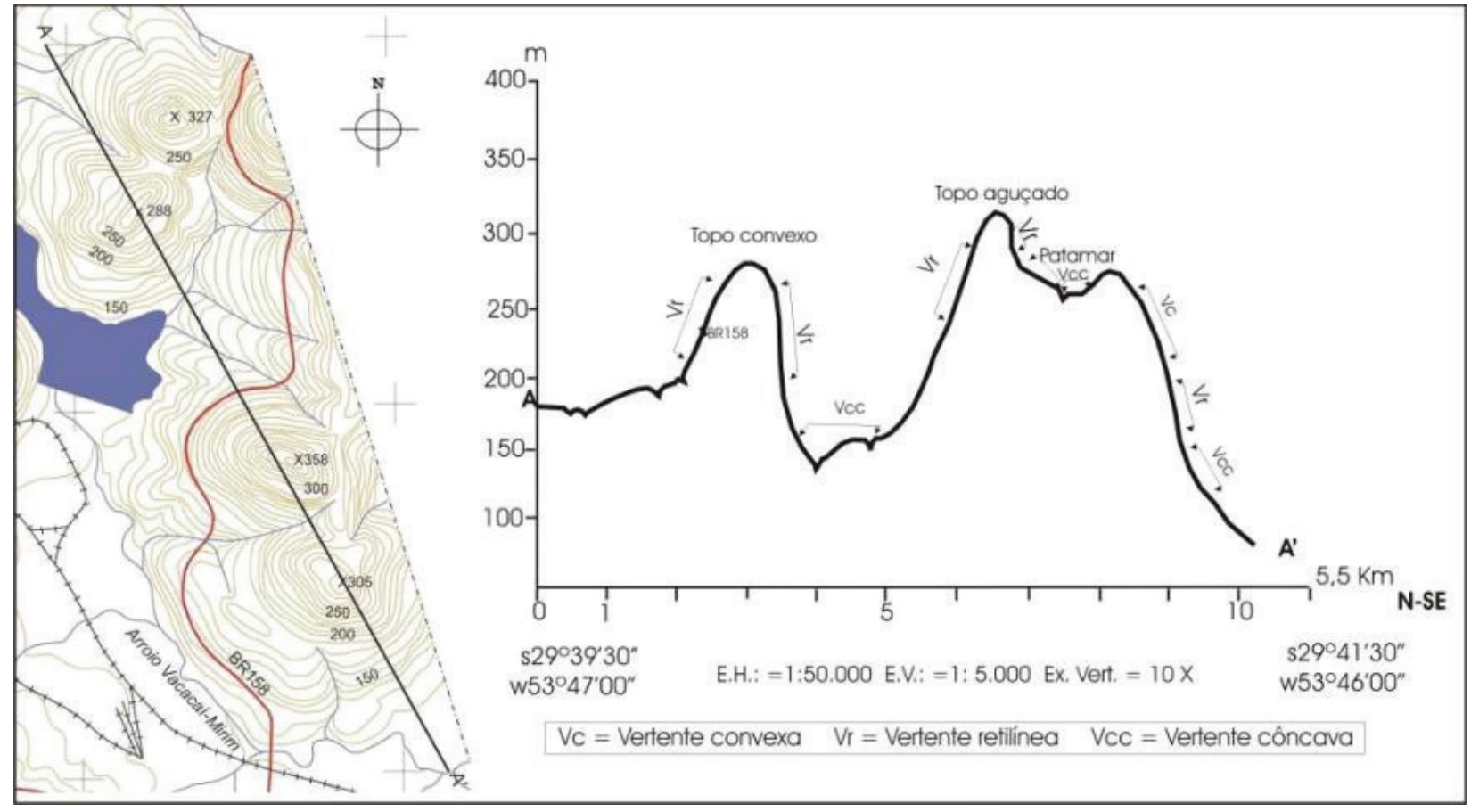

Figura 4 - Perfil topográfico da morfologia e morros

Fonte: Carta Topográfica de Santa Maria SH.22-V-C-IV-1

O perfil topográfico traçado no sentido norte-sudeste - A A' (Figura 4), revela o predomínio de vertentes retilíneas compostas ora por escarpas abruptas, em forma de morros com topos arredondados (convexos) ou aguçados, ora por degraus ou patamares que decaem rumo às terras mais baixas da Depressão Periférica Sul-rio-grandense, dependendo da intensidade da ação erosiva.

Esse perfil comprova a irregularidade do relevo devido às grandes diferenças altimétricas desse setor, que chegam a 250 metros de amplitude entre o fundo do vale, nos 100 metros, e o topo mais alto que está na faixa dos 360 metros.

No setor sudoeste, onde localiza-se a parte da zona urbana, principalmente a vila Bilibio, pertencente ao bairro Quilômetro Três, as declividades acentuadas associadas às formas convexas das vertentes e à impermeabilização do solo pela pavimentação proporcionam uma baixa infiltração de água no solo. Esse fator aumenta o escoamento superficial, que se torna mais acelerado, concentrando-se nas áreas de vale, provocando erosão e/ou assoreamento nas redes de drenagem à jusante. $\mathrm{O}$ processo de escoamento acelerado contribui para o transporte de dejetos e materiais poluentes para os corpos de água, tornando essas áreas vulneráveis à erosão do solo e à contaminação das águas.

A formação geológica predominante neste compartimento de relevo é a Formação Caturrita
(Figura 5), formada de arenitos finos a médios, com cores rosa a cinza-claro e matriz argilo-síltica. Apresentam camadas de grande presença que se intercalam ou passam lateralmente a siltitos e folhelhos micáceos avermelhados.

Os arenitos mostram estratificação cruzada acanalada e planar. Essa formação apresenta-se com fácies arenosas de origem fluvial. Os arenitos da Formação Caturrita apresentam, em geral, baixa resistência à erosão, principalmente quando o solo superficial é retirado, o que provoca o avanço rápido da erosão com a formação de sulcos no terreno. Os problemas geotécnicos estão associados, principalmente, à possibilidade de escorregamento e de queda de blocos de rochas (MACIEL FILHO, 1990).

No topo dos morros encontra-se a Formação Serra Geral (Figura 5). Essa formação originou-se do vulcanismo fissural que ocorreu na bacia do Paraná. É reconhecida por três tipos litológicos distintos: basaltos e andesitos toleíticos (negros, subfaneríticos, maciços ou vesiculares); riodacitos e riolitos do tipo Palmas (afíricos, com textura e matriz granofírica); quartzo latitos e riolitos do tipo Chapecó (porfiríticos com textura vitrofírica).

Sobre os basaltos da Formação Serra Geral, de acordo com Maciel Filho (1990), ocorrem solos litólicos, constituídos por fragmentos basálticos, de baixa estabilidade nos taludes e com intensos movimentos de massa (rastejos e corridas de terra durante chuvas 


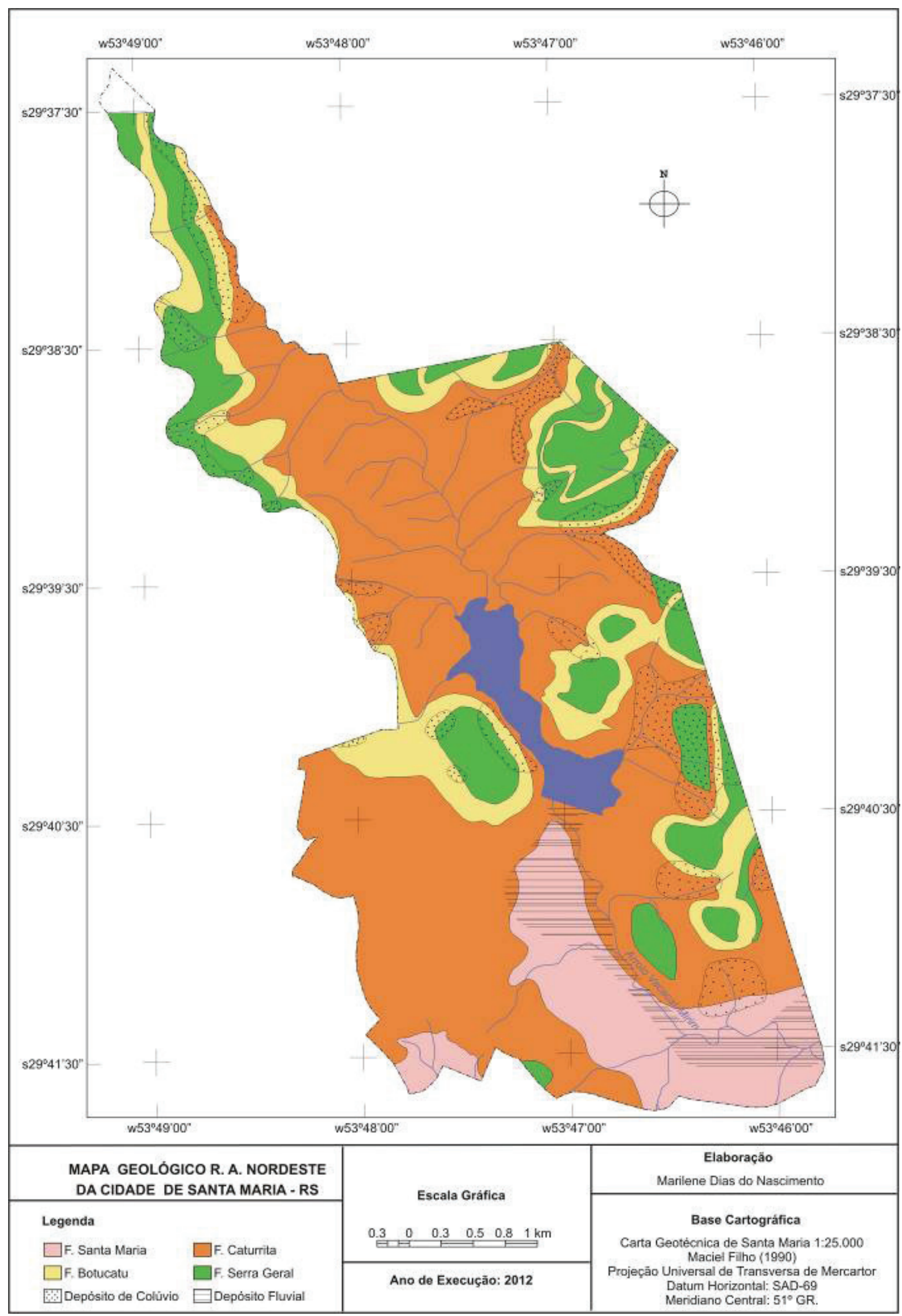

Figura 5 - Mapa Geológico da R. A. Nordeste 


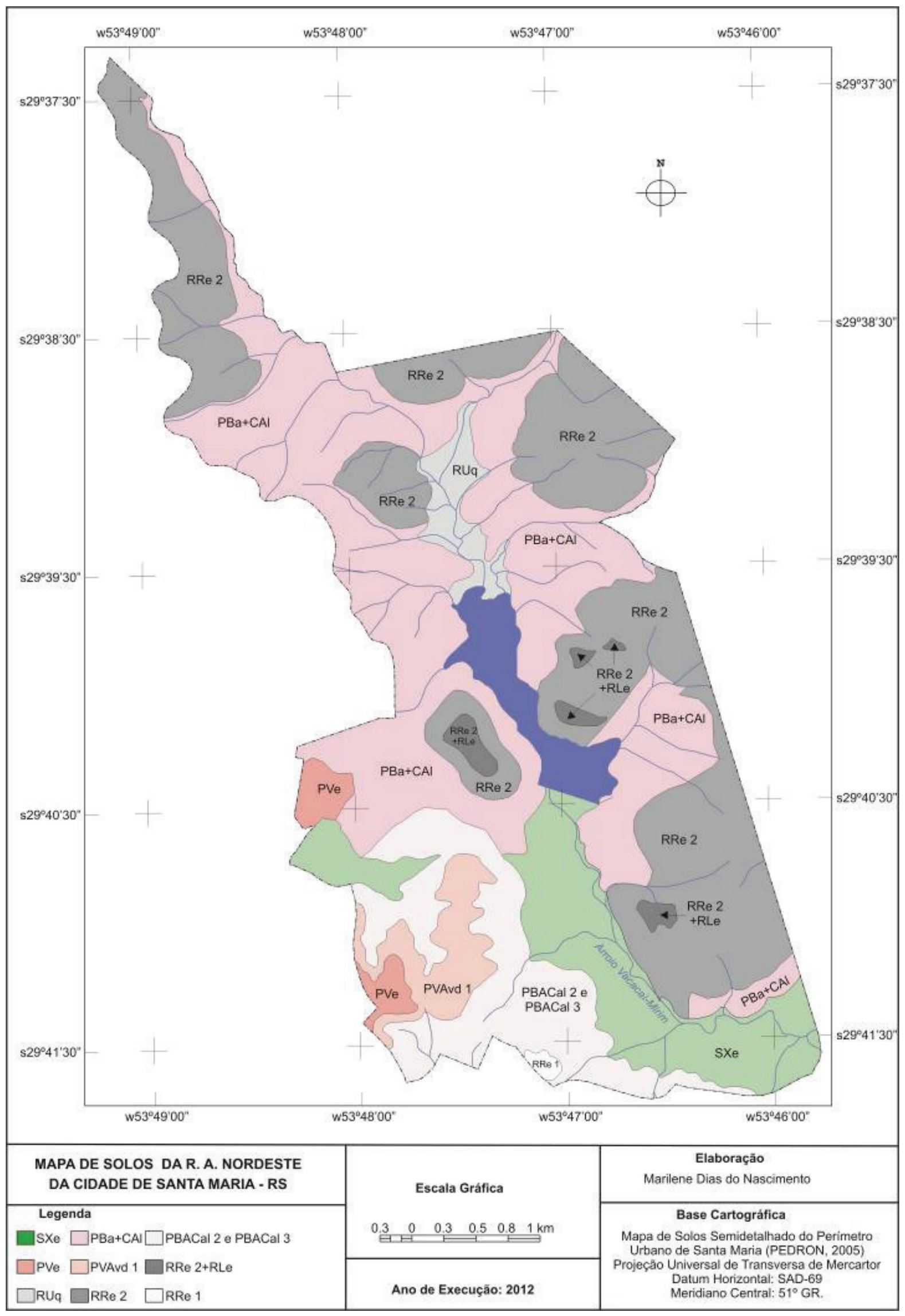

Figura 6 - Mapa de Solos da R. A. Nordeste 
intensas). O autor salienta, ainda, que os riolitos da Formação Serra Geral possuem comportamento semelhante aos basaltos da mesma unidade.

O Rebordo do Planalto apresenta depósitos de colúvio e grande quantidade de fraturamentos seccionados e descontínuos, comportando-se como área de descarga. As vertentes muito íngremes apresentam rochas expostas, onde a ação da água nas fraturas pode desencadear tombamentos e quedas de blocos. Já nas porções mais baixas da vertente ocorrem depósitos de colúvio e depósitos de rejeito sujeitos a escorregamentos. O local mais crítico, por ser muito urbanizado, é a vila Bilibio, no leste da R. A. Nordeste.

Exposta nas porções intermediárias e basais do Rebordo do Planalto, a Formação Botucatu (Figura 5) ocorre em cotas superiores a 200 metros e com declividades que variam de 12 a 20\%. Sua espessura máxima não ultrapassa os 70 metros. É constituída por arenitos médios a finos, com cores rosa - claro a avermelhado. Apresenta estratificação cruzada tangencial de grande porte, o que evidencia sua origem eólica.

$\mathrm{O}$ arenito Botucatu, segundo Maciel Filho (1990), possui comportamento geotécnico que varia desde rocha dura e muito abrasiva, em locais próximos do topo e junto a escarpas, até arenito brando e areia com pouca coesão, quando alterado. Nas partes fortemente litificadas, possui alta resistência à erosão, porém essa resistência é baixa nas partes alteradas e de solo residual. Os problemas geotécnicos estão associados, principalmente, à possibilidade de escorregamento e de queda de blocos de rochas.

Os solos predominantes neste compartimento de relevo são os Neossolos (Figura 6).

Esses solos têm como material de origem os arenitos da Formação Caturrita, situados no terço superior das coxilhas onduladas, localizadas no sopé do Rebordo do Planalto, ou são formados por material originário dos basaltos da Formação Serra Geral, localizados nos topos dos morros. Geralmente apresentam ausência de pedregosidade e de rochosidade e são bem drenados. São solos pouco profundos que apresentam variações na espessura e sequência dos horizontes. Podem aparecer variações como Neossolos Litólicos e inclusões como Cambissolos e Chernossolos. Além idsso, são solos que apresentam potencial restrito para construções urbanas, sendo indicado o uso com áreas verdes e recreativas, devido às limitações como declividade, profundidade do perfil e textura do solo (PEDRON et al, 2008).

\subsubsection{Unidade Morfológica de Colinas}

Abrange 32,10\% da área (Figura 2). Caracterizase pelo predomínio de vertentes médias com altitudes entre 130 e 200 metros e declividades médias entre 6 e 20\% (Figura 3). Correspondem aos patamares mais baixos das escarpas do Rebordo do Planalto.

O relevo é ondulado com topos convexos, onde se destacam os processos de erosão. O relevo de colinas caracteriza-se por pequenas elevações arredondadas (desníveis altimétricos até 50 metros) e declives suaves, cujo topo tende para a convexidade e pode corresponder a uma forma tanto denudacional como agradacional. Quando o topo dessas colinas é plano e com área expressiva são denominadas mesas e quando suas vertentes são sensivelmente convexas, assumindo a forma de um cone com vértice arredondado, são denominadas mamelão (NASCIMENTO, 2007).

Sobre essa unidade encontra-se a maior parte da área do bairro Nossa Senhora das Dores, do bairro Menino Jesus e parte do bairro Campestre do Menino Deus.

O perfil topográfico - B B' - (Figura 7), traçado no sentido oeste-sudeste, numa extensão de 5

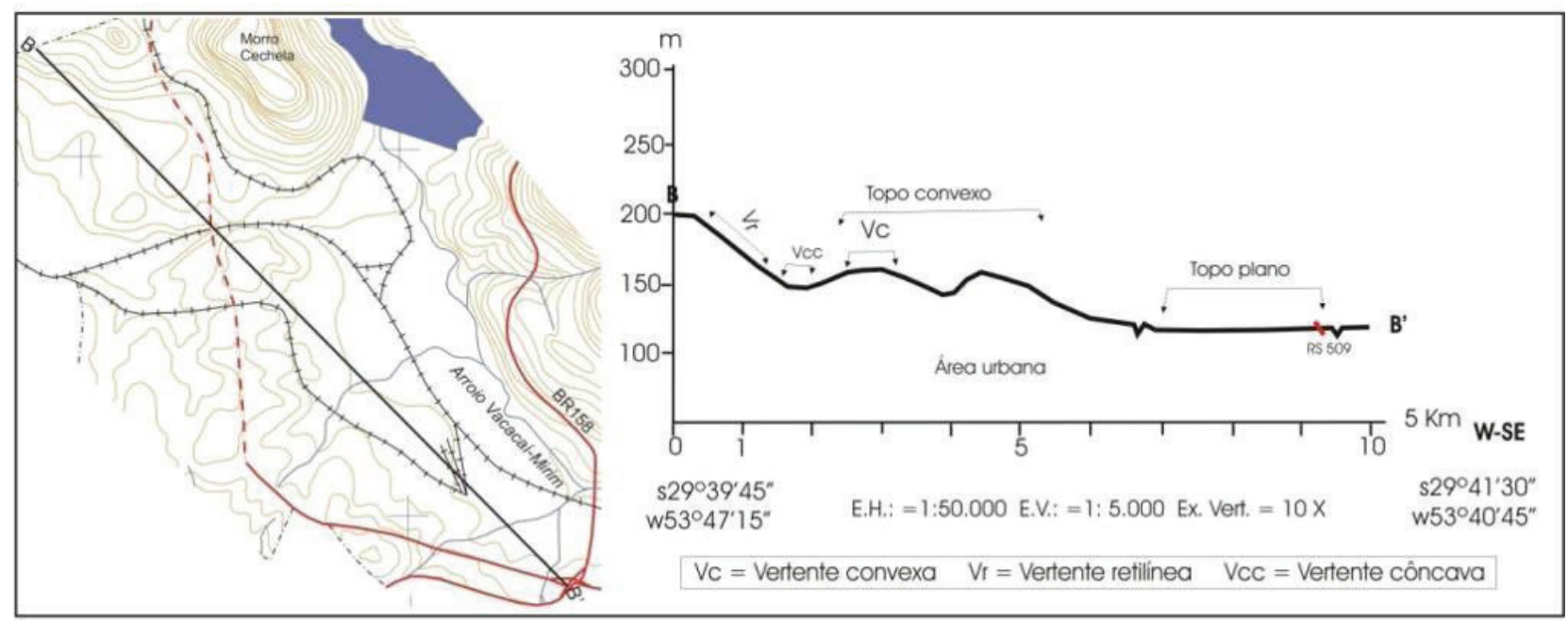

Figura 7 - Perfil topográfico da morfologia de colinas

Fonte: Carta Topográfica de Santa Maria SH.22-V-C-IV-1 
$\mathrm{Km}$, engloba parte da área densamente urbanizada da R. A. Nordeste de Santa Maria e define um relevo levemente ondulado, com formas regularmente distribuídas, de topos planos a convexos, com vertentes côncavas próximas ao leito do rio Vacacaí Mirim e retilíneas a convexas nos locais mais elevados. Esse perfil revela, também, as formas suaves de relevo, fracamente ondulado.

Nessa unidade predominam os Argissolos, originados principalmente pela alteração dos arenitos da Formação Caturrita (Figura 6). Estes solos são medianamente profundos, com sequência de horizontes $\mathrm{A}, \mathrm{Bt}_{1}, \mathrm{Bt}_{2}, \mathrm{BC}$ e $\mathrm{C}$, com incremento de argila do horizonte A para o $\mathrm{B}$.

Conforme Pedron et al. (2008), são solos que apresentam potencial restrito de uso para construções urbanas, sendo indicado o uso com áreas verdes e recreativas, devido a limitações como profundidade do solo, drenagem e material geológico.

\subsubsection{Unidade Morfológica de Planícies Fluviais}

Os outros 19\% da área correspondem à unidade de relevo de planícies aluviais do arroio Vacacaí Mirim (Figura 2), situadas em altitudes entre 110 e 130 metros, ao longo do rio Vacacaí Mirim, a montante e a jusante do reservatório do DNOS. Constitui o vale do rio Vacacaí Mirim e caracteriza-se por terrenos planos com declividades inferiores a $6 \%$, consideradas fracas, próprias de relevos planos ou quase planos, onde o escoamento superficial é lento ou muito lento. O declive do terreno não oferece dificuldades aos implementos e máquinas agrícolas e aceita urbanização e infraestruturas viárias. No entanto, como neste caso, referem-se principalmente às planícies fluviais do rio Vacacaí Mirim, onde predominam os processos de deposição em áreas de inundação. Nessa unidade se insere parte da área dos bairros Quilômetro Três e João Goulart.

A formação geológica predominante é a Formação Santa Maria (Figura 5). Essa Formação subdivide-se nos membros Passo das Tropas e Alemoa. O Membro Passo das Tropas, basal, é constituído por arenitos grossos a médios, róseo - avermelhados, feldspáticos, tornando-se conglomeráticos em direção à base, com grânulos e seixos de quartzo. Possuem estratificação cruzada e camadas de siltitos arenosos vermelhos. O Membro Alemoa, superior, possui uma litologia monótona de siltito argiloso, compacto, maciço, de cor vermelho tijolo, algo micáceo. Tratase de um lamito de argilas expansíveis. A ocorrência desses lamitos impermeáveis não permite circulação das águas, inexistindo poços tubulares nesta unidade estratigráfica. $\mathrm{Na}$ área de estudo, ocorrem ainda os
Terraços Fluviais Pleistocênicos, constituídos por conglomerados, arenitos médios argilosos e siltitos arenosos fluviais, além de sedimentos aluviais recentes, representados por cascalhos, areias, siltes e argilas fluviais (GASPARETTO, et al. 1988).

Os solos encontrados nessa porção do relevo são, principalmente, os Planossolos, originários da Formação Santa Maria, apresentando textura média -argilosa (Figura 6). Estes solos são bastante profundos, apresentando sequência de horizontes $\mathrm{A}_{1^{\prime}}, \mathrm{A}_{2^{\prime}}, \mathrm{Btg}_{1} \mathrm{e}$ $\mathrm{Btg}_{2}$, com aumento significativo nos teores de argila do horizonte A para o B. O material de origem é o Membro Alemoa da Formação Santa Maria. O perfil é mal drenado, com ausência de pedregosidade e de rochosidade.

Quanto ao potencial de uso urbano, segundo Pedron et al (2008) apresentam potencial restrito para construções urbanas, sendo indicados para áreas verdes e recreativas, devido às limitações como risco de inundações, textura e drenagem.

Nessas planícies fluviais, há a interferência de processos superficiais agradacionais, decorrentes de processos de acumulação que, associado com o tipo litológico predominante, os tipos de solos, o regime de chuvas, o uso e a ocupação, a vegetação existente e os níveis de preservação ambiental pode apresentar riscos de inundações e erosões de margem em ocorrência de precipitações intensas.

\subsection{A cobertura vegetal e o uso do solo}

A R. A. Nordeste possui $45 \%$ de sua área com presença de florestas nativas, consideradas pelo Plano Diretor de Desenvolvimento Urbano Ambiental do Município de Santa Maria como Área de Influência da Reserva da Biosfera da Mata Atlântica. Essas são áreas de restrito acesso para ocupação humana, como no topo de morros e áreas com maior declividade, na porção nordeste da área de estudo, unidade morfológica de morros, junto ao morro Cechela, a oeste do reservatório do DNOS e nos morros residuais (Figura 8).

As florestas correspondem às Florestas Subcaducifólias Subtropicais, mantidas pelas condições climáticas nessa unidade de relevo, com alta umidade do ar, chuvas abundantes e nevoeiros. Atualmente, encontra-se muito devastada pelas atividades agrícolas e pela ocupação humana através da expansão urbana, que ocorre sem nenhuma orientação ou planejamento.

A área urbana ocupa $29,1 \%$ da R. A. Nordeste e é encontrada praticamente na unidade morfológica de colinas. Embora a área urbana concentre-se nesta porção da área de estudo, está avançando para áreas originalmente de florestas, com morfologia de morros, com declives superiores a $12 \%$, como é o caso das seguintes ocupações: (a) no bairro Itararé, como na 


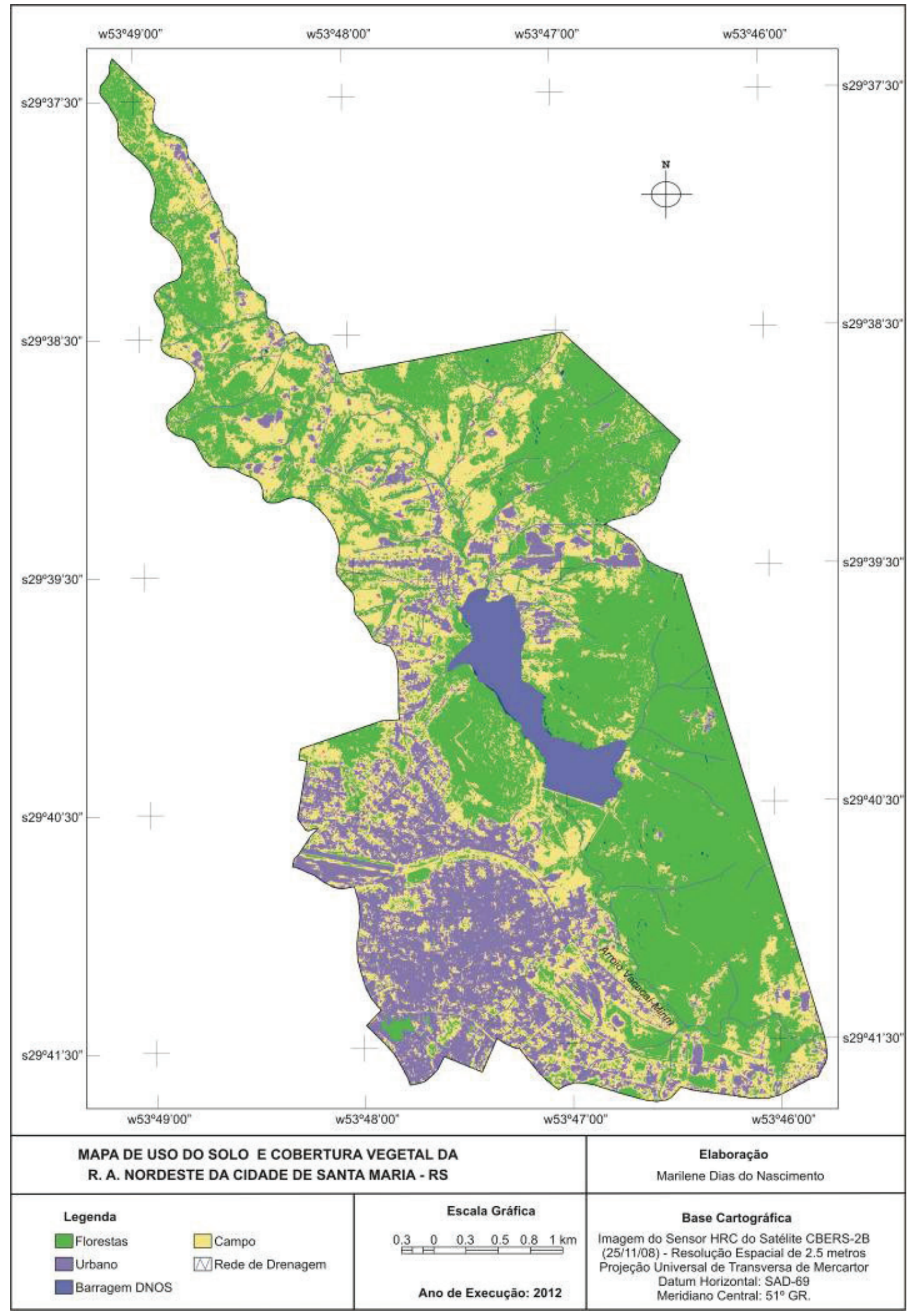

Figura 8 - Mapa de Uso do Solo e Cobertura Vegetal da R. A. Nordeste 
vila Bela Vista, unidade residencial urbana localizada no sopé do Morro Cechela; (b) na vila Canário, unidade residencial urbana localizada no extremo norte do Morro Cechela; (c) no Loteamento Link, unidade residencial localizada no sopé do morro Link; (d) em Possadas, unidade residencial, localizada ao nordeste do Morro do Monumento; (e) na vila Burger, unidade residencial urbana localizada ao sul do Morro Cechela; e (f) no bairro Km 3, a vila Bilibio, localizada a norte do Vacacaí Mirim em declividades superiores a 20\%.

De maneira geral, a ocupação é mais densa na base do morro, mas estende-se até a meia encosta. A porção situada mais próxima do topo ainda não está ocupada e encontra-se com cobertura vegetal de médio e grande porte.

A área considerada agrícola corresponde a $1,6 \%$ do total da área mapeada e corresponde a 0,3 $\mathrm{Km} 2$ ao norte do reservatório do DNOS. Nesse local, constatou-se, através de trabalho de campo, que a principal cultura desenvolvida é a plantação de cana, que serve de alimento para o gado e de pastagens, em pequenas propriedades.

A constituição vegetal formada por campos é encontrada em $21,7 \%$ da área de estudo, em relevo plano a suave ondulado de colinas. Há também a presença de matas ciliares ao longo de arroios e riachos e capões de mato.

\subsection{As fragilidades ambientais da R. A. Nordeste}

O estudo geomorfológico da paisagem da R. A. Nordeste da cidade de Santa Maria, integrando elementos físicos e antrópicos, permitiu a identificação das áreas de suscetibilidade e de fragilidades ambientais. Nesse estudo, constatou-se que a Unidade Morfológica de Morros, correspondente a 48,9\% da área estudada, é a unidade que apresenta os maiores conflitos ambientais e, por isso, pode ser considerada fortemente instável, pois o equilíbrio natural vem sendo afetado em vista as modificações antrópicas introduzidas na paisagem.

Causam preocupação as ocupações verificadas em locais com declividades acentuadas, acima dos $20 \%$, associadas a solos pouco consolidados, desenvolvidos sobre uma formação litológica com baixa resistência aos processos de erosão (Quadro 1), na unidade de morros, principalmente em torno do morro Cechela, vila Bela Vista, no bairro Itararé e na vila Bilibio, no bairro Quilômetro Três. Essa urbanização desordenada e não planejada contribui para elevar a fragilidade ambiental da área, causando desequilíbrio ambiental.

Em trabalho de campo, foram constatados cortes de aterro para construção de moradias de baixo padrão construtivo, bem como muros abaulados e rachados nas residências, sinais de movimentos lentos no relevo, do tipo rastejo.

Também foram identificadas, no local, árvores com raízes expostas, sinais de perda de solo por erosão laminar, além de árvores inclinadas, sinais de movimentos de massa do tipo rastejo. Além desses fatores, há o agravante da grande quantidade de lixo e esgoto a céu aberto, principalmente na ocupação do morro Cechela, no qual tanto o esgoto cloacal quanto a água servida e o lixo são lançados diretamente nas águas do reservatório, ocasionando contaminação da água que abastece parte da cidade. Considerando que esses locais estão em posições mais elevadas do relevo, por ocasião da chuva, o lixo e o esgoto são transportados diretamente para o leito do rio Vacacaí Mirim, promovendo a contaminação e assoreamento do mesmo.

Na unidade morfológica de colinas, embora

Quadro 1 - Resumo das Unidades Morfológicas da R. A. Nordeste Org. NASCIMENTO, M. D. do, 2012

\begin{tabular}{|c|c|c|c|c|c|c|c|c|c|}
\hline $\begin{array}{l}\text { Unidades } \\
\text { Morfológicas }\end{array}$ & $\begin{array}{l}\text { \%da } \\
\text { área }\end{array}$ & $\begin{array}{l}\text { Descrição } \\
\text { do relevo }\end{array}$ & $\begin{array}{l}\text { Desnível } \\
\text { altimétrico } \\
\text { (m) }\end{array}$ & $\begin{array}{c}\text { Declividades } \\
(\%)\end{array}$ & $\begin{array}{c}\text { Formação } \\
\text { litológica } \\
\text { predominante }\end{array}$ & $\begin{array}{l}\text { Tipos de } \\
\text { solos }\end{array}$ & $\begin{array}{l}\text { Processos } \\
\text { correlatos }\end{array}$ & $\begin{array}{c}\text { Usos } \\
\text { recomendados }\end{array}$ & Usos atuais \\
\hline $\begin{array}{l}\text { Unidade de } \\
\text { Morros }\end{array}$ & 48,9 & $\begin{array}{l}\text { Fortemente } \\
\text { ondulado }\end{array}$ & 250 & $\begin{array}{l}20 \text { a } 30 \% \text { e } \\
>30 \%\end{array}$ & $\begin{array}{l}\text { Formação } \\
\text { Serra Geral } \\
\text { (topo) } \\
\text { Formação } \\
\text { caturrita } \\
\text { (basal e média } \\
\text { vertente) }\end{array}$ & Neossolos & $\begin{array}{l}\text { Erosão e } \\
\text { movimentos } \\
\text { de massa }\end{array}$ & $\begin{array}{l}\text { Florestal e } \\
\text { reflorestamento, } \\
\text { não apto para } \\
\text { urbanização e } \\
\text { infraestruturas } \\
\text { urbanas }\end{array}$ & $\begin{array}{l}\text { Florestas } \\
\text { nativas } \\
\text { Urbanização } \\
\text { (base e meia } \\
\text { encosta) }\end{array}$ \\
\hline $\begin{array}{l}\text { Unidade de } \\
\text { Colinas }\end{array}$ & 32,10 & $\begin{array}{l}\text { Ondulado a } \\
\text { suavemente } \\
\text { ondulado }\end{array}$ & 70 & 6 a $20 \%$ & $\begin{array}{l}\text { Formação } \\
\text { Caturrita }\end{array}$ & Argissolos & $\begin{array}{l}\text { Erosão e } \\
\text { movimentos } \\
\text { de massa }\end{array}$ & $\begin{array}{l}\text { Pouco apto } \\
\text { para } \\
\text { urbanização e } \\
\text { infraestruturas }\end{array}$ & $\begin{array}{l}\text { Urbanização } \\
\text { consolidada }\end{array}$ \\
\hline $\begin{array}{l}\text { Unidade de } \\
\text { Planícies } \\
\text { Aluviais }\end{array}$ & 19 & $\begin{array}{l}\text { Plano ou } \\
\text { quase plano }\end{array}$ & 20 & $<6 \%$ & $\begin{array}{l}\text { Formação } \\
\text { Santa Maria }\end{array}$ & Latossolos & $\begin{array}{l}\text { Deposição } \\
\text { em áreas } \\
\text { de } \\
\text { inundação }\end{array}$ & $\begin{array}{l}\text { Não apto à } \\
\text { urbanização } \\
\text { (área de } \\
\text { inundação) }\end{array}$ & $\begin{array}{l}\text { Urbanização } \\
\text { (principalmente } \\
\text { ocupações } \\
\text { irregulares ás } \\
\text { margens do } \\
\text { rio) }\end{array}$ \\
\hline
\end{tabular}


o uso recomendado, em função das declividades, seja pouco apto para urbanização e infraestruturas urbanas, constata-se que a urbanização já está consolidada, como é o exemplo do bairro Nossa Senhora das Dores, destinado, basicamente, ao uso residencial e comercial. Como esse bairro apresenta alto padrão das construções, ainda que as declividades cheguem até $20 \%$, a fragilidade ambiental detectada é considerada fraca, uma vez que os comprimentos de rampa são de médios a longos e o relevo possui ondulações suaves. Embora essa unidade não apresente, no momento, problemas ambientais imediatos, medidas de controle e proteção são indispensáveis à mesma, para que ela não passe, futuramente, para uma classe de fragilidade ambiental forte ou muito forte.

Na unidade morfológica de planícies fluviais, de relevo plano, com declividades inferiores a $6 \%$, as fragilidades ambientais são de natureza genética agradacional, cujo modelado constitui-se, basicamente, da planície fluvial do rio Vacacaí Mirim. Embora, em função das declividades, não apresentem problemas para a implantação da urbanização, detecta-se que a presença de ocupações não planejadas na área de inundação do rio contribui para uma fragilidade ambiental forte nesse local, uma vez que são responsáveis pela poluição e assoreamento do rio, em razão dos depósitos de lixo em suas margens e do despejo de esgoto a céu aberto, que são transportados, em ocorrência de chuvas, diretamente para o seu leito.

\section{Recomendações e considerações finais}

Diante dos resultados obtidos na presente pesquisa e com a finalidade de um melhor ordenamento do espaço municipal urbano, de modo a redistribuir os benefícios gerados pelo processo de urbanização e, ao mesmo tempo, preservar a qualidade ambiental, confere-se as seguintes manifestações, como recomendações e diretrizes de ações para a R. A. Nordeste da sede do município de Santa Maria/ RS: a) regulamentação do uso e ocupação do solo urbano de acordo com a capacidade da infraestrutura instalada e a diferenciação das áreas; b) restrição do adensamento na área de inundação do rio Vacacaí Mirim; c) contenção da ocupação urbana na direção norte e nordeste, de morfologia de morros, da R. A. Nordeste; d) definição de indicadores ambientais e urbanos para monitorar a expansão e a ocupação urbana; e e) definição de critérios de adensamento, uso e ocupação diferenciados, de acordo com as distinções de fragilidade de cada área.

Considerando o que foi exposto e conside- rando, também, a implementação de uma política de gerenciamento mais abrangente onde, além da administração pública, sejam envolvidas entidades de classe, grupos organizados, além do envolvimento direto da população, o controle e a preservação dos recursos naturais podem conviver com o uso racional destes, ou seja, onde o uso que se faça da terra seja compatível com o grau de fragilidade dos aspectos físicos como declividades do terreno, tipo de solos e modelado do relevo.

\section{Referências}

GASPARETTO, N. V. L; MACIEL FILHO, C.L.; SARTORI, P. L. P.; VEIGA, P. Mapa Geológico da Folha de Camobi - RS. Texto explicativo. Santa Maria: FINEP/ UFSM, 1988. 10 p.

GOLDANI, J. Z.; CASSOL, R. Ocupação antrópica e sócio-ambiental da microbacia do rio Vacacaí-Mirim - RS. Geomática. Vol. 3, N. 1 e 2, 2008, p. 43 a 55.

IBGE. Censo Demográfico 2010. 2010. Disponível em <www.ibge.gov.br>. Acesso em: 28 outubro 2012.

MACIEL FILHO, C. L. Carta Geotécnica de Santa Maria (1:25.000). Santa Maria: UFSM, 1990. 21 p.

MINISTÉRIO DO EXÉRCITO. Diretoria de Serviços Geográficos. Carta Topográfica de Santa Maria, Folha SH. 22-V-C-IV-1.

NASCIMENTO, M. D. do. Análise geomorfológica da carta topográfica de Santa Maria - RS. 2007.

Trabalho de Graduação (Graduação em Geografia Bacharelado), Universidade Federal de Santa Maria, 2007.

PEDRON, F. de A.; DALMOLIN, R. S. D.; AZEVEDO, A. C. Solos do Perímetro Urbano de Santa Maria: características, classificação e potencial de uso. 1. Ed. Santa Maria: Orium, 2008. v. 1.143 p.

PENTEADO, M. M. Geografia e Planejamento. A Geomorfologia no Contexto Social. Instituto de Geografia da Universidade de São Paulo. 1981.

PREFEITURA MUNICIPAL DE SANTA MARIA. Lei complementar municipal no 042 de 29 de dezembro de 2006: Disponível em: <http://www. santamaria.rs.gov.br/>. Acesso em: 20 jun.2012. 
PREFEITURA MUNICIPAL DE SANTA MARIA. Plano Diretor de Desenvolvimento Urbano Ambiental (PDDUA) de Santa Maria - RS. 2006. Disponível em <www.santamaria.rs.gov.br/>. Acesso em 28 de junho 2012.

ROSS, J. L. S. Análise empírica da fragilidade dos ambientes naturais e antropizados. In: Revista do Departamento de Geografia; n.8, p. 63 - 74. São Paulo, USP, 1994.

ROSS, J. L. S. Geomorfologia aplicada aos EIAsRIMAs. In: GUERRA, A.J.T., CUNHA, S.B.

Geomorfologia e meio ambiente. Rio de janeiro: Bertrand Brasil, 1996. Cap. 7, p. 291-336.

ROSS. J. L. S. O registro cartográfico dos fatos geomorfológicos e a questão da taxonomia do relevo. Revista do Departamento de Geografia. São Paulo. 1992, n. 6, p. 17-29.

SOUZA, B. S. P. e. A qualidade da água de Santa Maria/ RS: uma análise ambiental das sub-Bacias hidrográficas dos rios Ibicuí Mirim e Vacacaí mirim. 2001. 234 f. Tese de Doutorado (Doutorado em Geografia Física) - Universidade de São Paulo, 2001. 